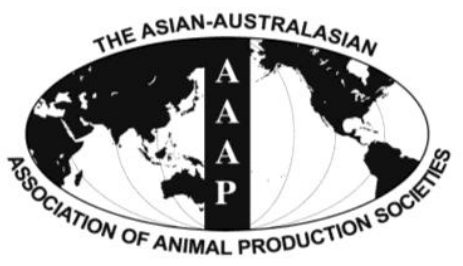

Open Access

Asian Australas. J. Anim. Sci.

Vol. 27, No. 9 : 1270-1275 September 2014

http://dx.doi.org/10.5713/ajas.2013.13786

www.ajas.info

pISSN 1011-2367 elSSN 1976-5517

\title{
Follicle Stimulating Hormone (FSH) Dosage Based on Body Weight Enhances Ovulatory Responses and Subsequent Embryo Production in Goats
}

\author{
M. R. Rahman ${ }^{1,2}$, M. M. Rahman ${ }^{1}$, W. E. Wan Khadijah ${ }^{1}$, and R. B. Abdullah ${ }^{1, *}$ \\ ${ }^{1}$ Animal Biotechnology-Embryo Laboratory (ABEL), Institute of Biological Sciences, Faculty of Science, \\ University of Malaya, 50603 Kuala Lumpur, Malaysia
}

\begin{abstract}
An experiment was conducted to evaluate the efficacy of porcine follicle stimulating hormone (pFSH) dosage based on body weight $(\mathrm{BW})$ on ovarian responses of crossbred does. Thirty donor does were divided into 3 groups getting pFSH dosages of 3,5 , and $8 \mathrm{mg}$ pFSH per kg BW, respectively, and were named as pFSH-3, pFSH-5 and pFSH-8, respectively. Estrus was synchronized by inserting a controlled internal drug release (CIDR) device and a single injection of prostaglandin F2 $\alpha$ (PGF2 $\alpha$ ). The pFSH treatments were administered twice a day through 6 decreasing dosages $(25,25,15,15,10$, and $10 \%$ of total pFSH amount; decreasing daily). Ovarian responses were evaluated on Day 7 after CIDR removal. After CIDR removal, estrus was observed 3 times in a day and pFSH treatments were initiated at 2 days before the CIDR removal. All does in pFSH-5 and pFSH- 8 showed estrus signs while half of the does in $\mathrm{pFSH}-3$ showed estrus signs. No differences $(\mathrm{p}>0.05)$ were observed on the corpus luteum and total ovarian stimulation among the treatment groups, while total and transferable embryos were higher $(\mathrm{p}<0.05)$ in pFSH-5 (7.00 and 6.71) than pFSH-3 (3.00 and 2.80$)$ and pFSH-8 (2.00 and 1.50), respectively. In conclusion, $5 \mathrm{mg}$ pFSH per kg BW dosage gave a higher number of embryos than 3 and $8 \mathrm{mg}$ pFSH per kg BW dosages. The results indicated that the dosage of pFSH based on BW is an important consideration for superovulation in goats. (Key Words: Superovulation, pFSH Dosage, Body Weight, Goat)
\end{abstract}

\section{INTRODUCTION}

Superovulation is a term used to describe the administration of exogenous gonadotrophin to induce the growth and maturation of many ovarian follicles to increase the number of mature ovum for fertilization (Baldassarre et al., 2003). Embryo recovery from donor and transfer of recovered embryo to synchronized recipient is considered as an effective means of increasing the contribution of superior females to the gene pool. However, the result of any superovulation programme is inconsistent and can fluctuate from complete failure to total success without any change in the standard operating procedure (Baldassarre and Karatzas, 2004). This variation in ovarian response

\footnotetext{
* Corresponding Author: R. B. Abdullah. Tel: +60-379674366, Fax: +60-379674366, E-mail: ramli@um.edu.my

${ }^{2}$ School of Agriculture and Rural Development, Bangladesh Open University, 1705 Gazipur, Bangladesh.

Submitted Dec. 3, 2013; Revised Feb. 16, 2014; Accepted Apr. 14, 2014
}

occurs not only between treatments but also within treatment. This may be attributed by many intrinsic and extrinsic factors including season, breed, donor age, nutrition, purity and source of gonadotropin and treatment protocols (Gonzalez-Bulnes et al., 2004).

Superovulation can be performed using exogenous gonadotrophin such as equine chorionic gonadotrophin (Goel and Agrawal, 2005), horse anterior pituitary (Moore, 1974) and follicle stimulating hormone (FSH) (Abdullah et al., 2012). Due to a short half-life and better embryo production performance compared to other gonadotrophins, FSH is preferable as a stimulatory agent in any multiple ovulation and embryo transfer (MOET) programme (Holtz, 2005). However, various factors (e.g., ratio of FSH and luteinizing hormone (LH) in hormone preparations, route of administration, dosage and frequency of injection) are involved on FSH superovulatory performance (Nowshari et al., 1995; Lehloenya and Greyling, 2009; Yuan et al., 2011). Superovulatory treatment of porcine follicle stimulating

Copyright (? 2014 by Asian-Australasian Journal of Animal Sciences This is an open-access article distributed under the terms of the Creative Commons Attribution Non-Commercial License (http://creativecommons.org/licenses/by-nc/3.0/), which permits unrestricted non-commercial use, distribution, and reproduction in any medium, provided the original work is properly cited. 
hormone ( $\mathrm{pFSH}$ ) in goat mainly consists of $200 \mathrm{mg} \mathrm{pFSH}$ without consideration of body weight $(\mathrm{BW})$ of the goat, which varies from 28 to $68 \mathrm{~kg}$, and also produces variable results (Menchaca et al., 2007; Lehloenya and Greyling, 2010; Xiao et al., 2013). Thus, the dosage of gonadotrophin might be a cause of variation in superovulation response. Theoretically, it seems that the goat with larger BW needs more pFSH than the smaller goat. Some researchers used different dosages of $\mathrm{pFSH}$ for superovulation without considering the BW of goat (Chang et al., 2006; Yuan et al., 2011; Abdullah et al., 2012) and cattle (Ali et al., 2012). Furthermore, the mature BW of goats varies among breeds. However, there is limited information regarding the use of pFSH dosage based on BW of goats. Hence, it is necessary to know the suitable dosage range according to $\mathrm{BW}$ for successful embryo transfer programme. Therefore, the objective of the present study was to evaluate the effect of different dosages of pFSH on ovarian stimulation and embryo production performance of Boer crossbred goats.

\section{MATERIALS AND METHODS}

\section{Location of experiment}

This experiment was carried out at the Institute of Biological Sciences Mini Farm (at a location of $2^{\circ} 30^{\prime} \mathrm{N}$, $\left.112^{\circ} 30^{\prime} \mathrm{E}\right)$, the University of Malaya, Malaysia. This location is $60 \mathrm{~m}$ above sea level and has an annual rainfall of $2600 \mathrm{~mm}$. All animals used in this experiment were in accordance with the guidelines of the University of Malaya.

\section{Experimental animal management}

Thirty mature crossbred does (local $\times$ Boer) of 17 to 36 $\mathrm{kg} \mathrm{BW}$ and 24 to 60 months of age were used for this experiment. The experimental does were divided into 3 groups and termed as pFSH-3, pFSH-5 and pFSH- 8 . The pFSH-3, pFSH-5 and pFSH-8 groups were administered 3, 5 and $8 \mathrm{mg}$ pFSH per $\mathrm{kg} \mathrm{BW}$, respectively. The average BW of the does of pFSH-3, pFSH-5, and pFSH-8 groups were $29.50,28.81$, and $25.00 \mathrm{~kg}$ respectively. The experimental does were reared under an intensive management system and received fresh soya waste $(20 \%$ dry matter) at a rate of $1 \mathrm{~kg} / \mathrm{h}$ ead $/ \mathrm{d}$. The soya waste contained $27.9 \%$ crude protein, $30.5 \%$ neutral detergent fibre and $5.3 \%$ ash. Soya waste was offered to the animal once in the morning, while the Napier grass (Pennisetum purpureum) was offered in the morning and afternoon. All animals had free access to water and salt lick. The study was conducted between October 2012 and April 2013.

\section{Ultrasonography of experimental animals}

All the donor does were scanned to identify the pregnancy status using an ultrasound machine (ALOKA SSD 500, Hitachi Aloka Medical, Ltd. Tokyo, Japan) equipped with a $7.5 \mathrm{MHz}$ transrectal probe. The tip of the probe was lubricated with carboxyethylcellulose contact gel and was gently inserted until the urinary bladder was identifiable. The probe was moved gently forward and backward and rotated at $90^{\circ}$ clockwise and $180^{\circ}$ counterclockwise to identify both ovaries. Only non-pregnant does were used for this experiment.

\section{Estrus synchronization and superovulation treatments}

For estrus synchronization, a controlled internal drug release (CIDR) dispenser was inserted (D0; 0800 to $0900 \mathrm{~h}$ ) for 14 days (D14; 0800 to $0900 \mathrm{~h}$ ) and a single injection of $125 \mu \mathrm{g}$ prostaglandin F2 $\alpha$ (PGF2 $\alpha$ ) (Estrumate; Intervet International B.V. Boxmeer, The Netherlands) was administered intramuscularly 1 day before starting the pFSH treatment (D11). The pFSH treatments were initiated at 2 days before the CIDR removal (D12), and were administered twice a day through multiple intramuscular injections. Subsequently, all the donor does were divided randomly into 3 groups, namely $\mathrm{pFSH}-3, \mathrm{pFSH}-5$, and pFSh-8. pFSH-3, pFSH-5, and pFSH-8 were administered with 3,5 , and $8 \mathrm{mg}$ of pFSH (Folltropin-V; Bioniche Life Sciences Inc, Ontario, Canada) based on per $\mathrm{kg} \mathrm{BW}$ through multiple intramuscular injections, respectively. Total amount of pFSH for each donor was divided into six decreasing $(25,25,15,15,10$, and $10 \%)$ dosages and given twice daily (0800 to $0900 \mathrm{~h}$ and 1800 to $1900 \mathrm{~h}$ ) for a period of three successive days. Based on these percentages, the absolute amount of pFSH per $\mathrm{kg} \mathrm{BW}$ was $0.75,0.75$, $0.45,0.45,0.30$, and $0.30 \mathrm{mg}$ for $\mathrm{pFSH}-3 ; 1.25,1.25,0.75$, $0.75,0.50$, and $0.50 \mathrm{mg}$ for $\mathrm{pFSH}-5$; and 2.00, 2.00, 1.20, $1.20,0.80$, and $0.80 \mathrm{mg}$ for $\mathrm{pFSH}-8$, respectively. Correspondingly, the ranges of $\mathrm{pFSH}$ administered per doe were 60 to 123,110 to 180 , and 136 to $276 \mathrm{mg}$, for pFSH-3, pFSH-5 and pFSH- 8 groups, respectively.

\section{Estrus detection and natural mating}

After CIDR withdrawal, estrus was observed 3 times in a day (morning, afternoon and evening) until exhibition of overt estrus by placing a buck of proven libido. After showing the signs of estrus, the doe was placed in a pen with a male for natural mating and AI was done simultaneously at 48 and 72 hours after CIDR removal.

\section{Surgical procedure for ovarian responses assessment}

On Day 7 after CIDR removal, ovarian responses were evaluated and embryos were collected during a laparotomy session. The donor goats were off-feed and off-water for 16 to 20 hours before surgery. For goat anesthesia, xylazine hydrochloride was mixed with ketamine hydrochloride at a ratio of 1:50 and administered through intramuscular injection $(11 \mathrm{mg} / \mathrm{kg} \mathrm{BW})$. After anesthesia, the reproductive tract was exteriorised through a mid-ventral incision and the 
Table 1. Effect of pFSH dosages on ovarian stimulation

\begin{tabular}{|c|c|c|c|}
\hline \multirow[b]{2}{*}{ Parameter } & \multicolumn{3}{|c|}{ Dosages of pFSH per kg body weight } \\
\hline & $\begin{array}{c}\text { pFSH-3 (3 mg) } \\
(\text { Mean } \pm \text { SEM) }\end{array}$ & $\begin{array}{c}\text { pFSH-5 (5 mg) } \\
(\text { Mean } \pm \text { SEM })\end{array}$ & $\begin{array}{c}\text { pFSH-8 }(8 \mathrm{mg}) \\
(\text { Mean } \pm \text { SEM })\end{array}$ \\
\hline Number of does & 10 & 10 & 10 \\
\hline Number of does showing oestrus & 5 & 10 & 10 \\
\hline Average number of $\mathrm{CL} / \mathrm{doe}^{1}$ & $9.20 \pm 2.87^{\mathrm{a}}$ & $10.57 \pm 2.72^{\mathrm{a}}$ & $7.38 \pm 1.87^{\mathrm{a}}$ \\
\hline Average number of anovulatory follicle (AF)/doe ${ }^{2}$ & $0.20 \pm 0.20^{\mathrm{a}}$ & $3.50 \pm 1.83^{\mathrm{a}}$ & $6.20 \pm 2.05^{\mathrm{b}}$ \\
\hline Average number of ovarian stimulation $(\mathrm{CL}+\mathrm{AF}) / \mathrm{doe}^{2}$ & $9.40 \pm 2.79^{\mathrm{a}}$ & $10.90 \pm 1.92^{\mathrm{a}}$ & $12.10 \pm 2.61^{\mathrm{a}}$ \\
\hline
\end{tabular}

pFSH, porcine follicle stimulating hormone; SEM, standard error of mean; CL, corpus luteum.

${ }^{1}$ Considered only the donor goats had ovulation. ${ }^{2}$ Considered all the donor showed oestrus.

${ }^{\mathrm{a}, \mathrm{b}}$ Mean values with different superscripts within a row were significantly $(\mathrm{p}<0.05)$ different.

superovulatory responses were assessed by counting the corpus luteum (CL) and anovulatory follicles of both ovaries. Both the fallopian tubes were flushed using a flushing medium consisted of phosphate buffered saline supplemented with streptomycin, penicillin and polyvinylpyrrolidone. A two-way Foley catheter (Imex) was used for embryo flushing. The recovered structures (embryos plus unfertilized oocytes) in the flushing medium were evaluated and classified accordingly under a stereomicroscope (SZH10; Olympus Optical Co. Ltd, Tokyo, Japan).

\section{Statistical analysis}

The effect of dosages of gonadotrophin on ovarian stimulation and embryo production parameters was examined by one-way analysis of variance using SPSS software (version 16.0, Statistical Package for the Social Sciences software, Chicago, IL, USA). Regression procedure was carried out using MS Excel software to determine the relationship between body weight and estrus response. Results were expressed as the mean \pm standard error of mean, and differences and correlations were considered as significant when $\mathrm{p}<0.05$.

\section{RESULTS}

Ovarian stimulation of crossbred does as affected by different $\mathrm{pFSH}$ dosages is presented in Table 1. Donor does showed estrus after 24 hours upon CIDR removal. All the donor does $(100 \%)$ of pFSH-5 and pFSH-8 showed signs of standing estrus, however, half of the donor does of $\mathrm{pFSH}-8$ showed signs of standing estrus. Average numbers of CL for pFSH-3, pFSH-5, and pFSH-8 were 9.20, 10.57, and 7.38, respectively, and no significant $(p>0.05)$ differences were observed among the treatment groups. Numbers of anovulated follicles were significantly $(\mathrm{p}<0.05)$ higher in pFSH-8 (6.20) than in pFSH-3 (0.20) and pFSH-5 (3.50). Total ovarian stimulation was increased linearly with increasing the dosage of $\mathrm{pFSH}$ and was highest in $\mathrm{pFSH}-8$ (12.10) followed by pFSH-5 (10.90) and pFSH-3 (9.40). Out of ten, five donor does of pFSH-3 had no stimulation and only one donor does had anovulatory follicles. Three donor does in pFSH-5 and two donor does in pFSH-8 had no CL. Donor does with CL were only used in the result analysis.

Embryo production performances as affected by different dosages of pFSH are presented in Table 2. The number of CL was increased from pFSH-3 to pFSH-5 and then decreased from pFSH-5 to pFSH-8, but CL percentages ([no. of CL/total no. stimulation] $\times 100$ ) showed an inverse relationship with the increase of pFSH dosage, and the values were $97.87 \%, 67.89 \%$, and $48.76 \%$ for pFSH-3, pFSH-5, and pFSH-8, respectively. Although the average number of CL per doe for the three treated groups

Table 2. Effect of pFSH dosages on embryo production characteristics

\begin{tabular}{lccc}
\hline & \multicolumn{3}{c}{ Dosages of pFSH per kg body weight } \\
\cline { 2 - 4 } Parameter & $\begin{array}{c}\text { pFSH-3 }(3 \mathrm{mg}) \\
(\text { Mean } \pm \text { SEM) }\end{array}$ & $\begin{array}{c}\text { pFSH-5 }(5 \mathrm{mg}) \\
(\text { Mean } \pm \text { SEM) }\end{array}$ & $\begin{array}{c}\text { pFSH-8 (8 mg) } \\
(\text { Mean } \pm \text { SEM) }\end{array}$ \\
\hline Number of does flushed & 5 & 7 & 8 \\
Average number of embryos/doe & $3.00 \pm 1.14^{\mathrm{a}}$ & $7.00 \pm 1.86^{\mathrm{b}}$ & $2.00 \pm 0.73^{\mathrm{a}}$ \\
Average number of transferable embryos/doe & $2.80 \pm 1.02^{\mathrm{a}}$ & $6.71 \pm 1.95^{\mathrm{b}}$ & $1.50 \pm 0.71^{\mathrm{a}}$ \\
Average number of degenerated embryos/doe & $0.20 \pm 0.20^{\mathrm{a}}$ & $0.29 \pm 0.18^{\mathrm{a}}$ & $0.50 \pm 0.19^{\mathrm{a}}$ \\
Average number of structures recovered/doe & $4.00 \pm 1.00^{\mathrm{a}}$ & $7.14 \pm 1.80^{\mathrm{a}}$ & $4.25 \pm 1.33^{\mathrm{a}}$ \\
Recovery rate $\%$ \% & $59.73 \pm 13.53^{\mathrm{a}}$ & $69.22 \pm 4.55^{\mathrm{b}}$ & $60.74 \pm 9.94^{\mathrm{a}}$ \\
Average number of unfertilised oocytes/doe & $1.00 \pm 0.77^{\mathrm{a}}$ & $0.14 \pm 0.14^{\mathrm{a}}$ & $2.25 \pm 1.59^{\mathrm{a}}$ \\
\hline
\end{tabular}

pFSH, porcine follicle stimulating hormone; SEM, standard error of mean.

${ }^{a, b}$ Mean values with different superscripts within a row were significantly $(p<0.05)$ different. 
were similar, the total number of recovered embryos and transferable embryos per doe were significantly $(\mathrm{p}<0.05)$ higher in pFSH-5 (7.00 and 6.71) than in pFSH-3 (3.00 and $2.80)$ and in pFSH-8 (2.00 and 1.50), respectively (Figure 1). The number of structures (embryos plus unfertilized oocytes) recovered and the recovery rate per doe were higher in pFSH-5 (7.14 and 69.22) followed by pFSH-8 (4.25 and 60.74) and pFSH-3 (4.00 and 59.73), respectively (Table 2). The number of unfertilized oocytes per doe was lower in pFSH-5 (0.14) followed by pFSH-3 (1.00) and pFSH-8 (2.25), (Figure 2), but no differences ( $p>0.05$ ) were observed among treatment groups.

\section{DISCUSSION}

In this study, all the donor does of $\mathrm{pFSH}-5$ and $\mathrm{pFSH}-8$ showed the signs of estrus by using 14-day CIDR treatment. This value is similar to the findings of earlier researchers (Lehloenya et al., 2008; Lehloenya and Greyling, 2009) who recorded $100 \%$ estrus for Boer goats using 17 days CIDR and superovulated with pFSH. On the other hand, the present result was superior to some researchers who observed $87 \%$ and $75 \%$ estrus for Toggenburg goats (Fonseca et al., 2005; Zambrini, 2006). On the contrary, only $50 \%$ of does of pFSH-3 showed estrus in this study, and this result might be due to low dosage of $\mathrm{pFSH}$, which may not be able to stimulate the ovary. These data indicate that CIDR with a sufficient amount of pFSH is an effective means of estrus synchronization for Boer crossbred does.

Although ovulation rate was similar for all the groups, pFSH-5 produced significantly a higher number of embryos than other groups. However, ovulation rate was not represented by embryos, which also included the ovulated oocytes that failed to be fertilized. It implies that the superovulation effect was not boosted up by high and low

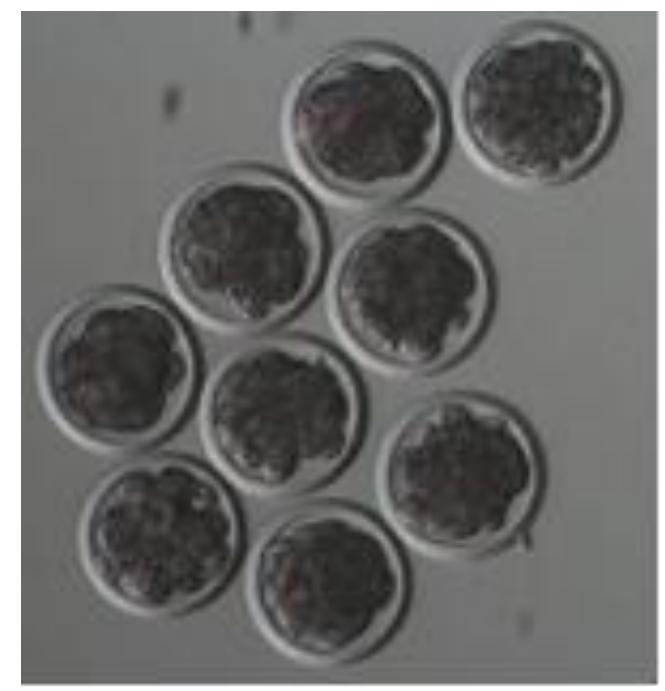

Figure 1. Recovered fresh embryos at $20 \times$ magnification.

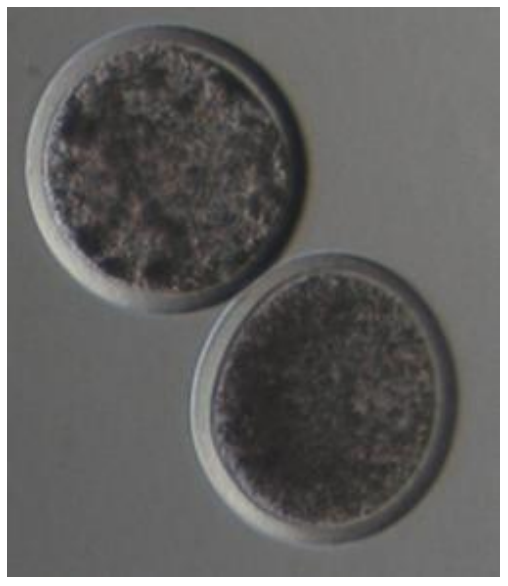

Figure 2. Recovered fresh unfertilised oocytes at 20x magnification.

dosages of exogenous pFSH. In superovulated does, reduced fertility occurred due to prolonged elevation in estrogen concentrations resulting from the large anovulatory follicles and the abnormal maturation of oocytes (Cameron et al., 1988; Kumar et al., 1991; Ryan et al., 1991). Moreover, high estradiol concentration around and/or beyond ovulation induced disorders on the later reproductive process of fertilization and embryo development (Veiga-Lopez et al., 2006). Results of the present study also are in line with the findings of Ryan et al. (1991). In this study, the numbers of total and transferable embryo recovered from $\mathrm{pFSH}-3$ and $\mathrm{pFSH}-8$ were lower than $\mathrm{pFSH}-5$. This result indicated that exogenous $\mathrm{pFSH}$ could promote ovarian responses, but the best superovulation results could be obtained only with a certain pFSH dosage range. However, the superovulation effect is not promoted by too high ( $>5 \mathrm{mg}$ per $\mathrm{kg} \mathrm{BW}$ ) and too low (<5 mg per $\mathrm{kg} \mathrm{BW}$ ) dosages of exogenous $\mathrm{pFSH}$ as suggested in this study. Too high dosage of exogenous pFSH reduced the number for embryo production by producing a higher number of anovulatory follicles, which might increase estrogen levels in the blood. Elevated estrogen level in blood impaired sperm transportation in the female reproductive system and the breakage of sperm cells, which resulted in a higher number of unfertilized oocytes (Conley and Hawk, 1970; Armstrong et al., 1983; Greve et al., 1995). On the other hand, a too low dosage of exogenous pFSH may not be sufficient for stimulation of folliculogenesis and maturation of follicles. In this study, $50 \%$ of animal showed stimulation, which might be due to coincidence with the internal FSH production and the exogenous $\mathrm{pFSH}$ treatment. For pFSH-3, estrus response was not correlated with the BW (Figure 3).

The highest numbers of total embryo recovery, transferable embryo and structured recovered were obtained by using $5 \mathrm{mg}$ pFSH per $\mathrm{kg} \mathrm{BW}$. These results were higher than the findings of previous studies (Menchaca et al., 


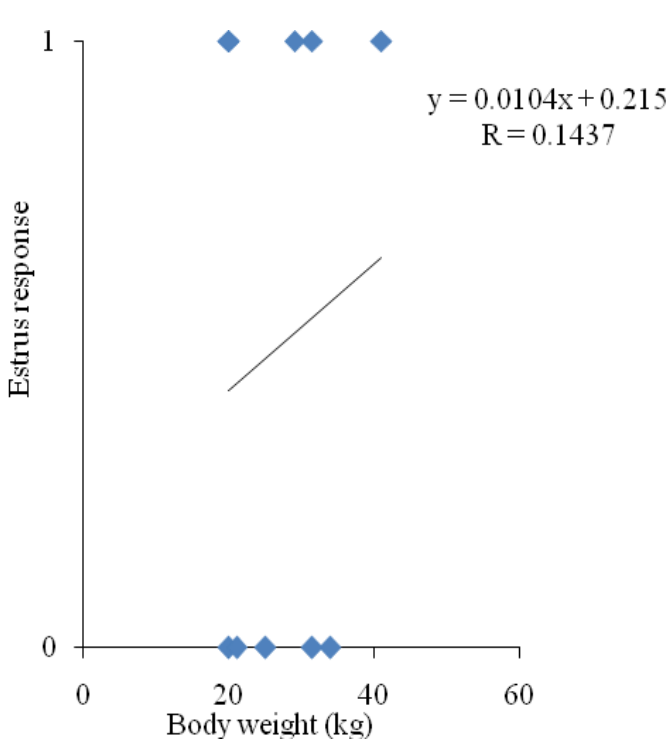

Figure 3. Correlation coefficient of body weight and estrus response for porcine follicle stimulating hormone-3.

2007; Abdullah et al., 2012; Xiao et al., 2013) but lower than the findings of an earlier study (Lehloenya, 2013). This result might be explained by the influence of breed, BW and nutrition (Bindon et al., 1986; Mani et al., 1992; Gonzalez-Bulnes et al., 2004; Abecia et al., 2006; Scaramuzzi et al., 2006).

Anovulatory follicles are obvious in the findings in any superovulatory protocols (Veiga-Lopez et al., 2006). In this study, the incidence was $22 \%$ to $45 \%$, which was similar to the findings of previous studies (Gonzalez-Bulnes et al., 2000; Abdullah et al., 2012). The anovulatory follicle number was increased with the increasing dosage of FSH and the highest number obtained in this study was similar with the findings of a previous study (Abdullah et al., 2012). For pFSH-3, pFSH-5 and pFSH-8, the number of goat had anovulated follicle was 1,3 , and 6 , respectively. This number was not enough to carry out correlation analysis between BW and anovulatory follicle. Therefore future studies involving dosages per $\mathrm{kg} \mathrm{BW}$ need to establish this relationship. The causal factor for anovulation may be the presence of LH in the FSH preparation, which alters the endocrine and ovarian function after administration of a high dosage of exogenous gonadotrophin, and results in a smaller size and defective maturation of follicles (Murphy et al., 1984; Noel et al., 1994; D’Occhio et al., 1999; Kendall et al., 2004; Veiga-Lopez et al., 2006).

The dosage of $\mathrm{pFSH}$ had a significant effect on the embryo production performance. Five $\mathrm{mg}$ of $\mathrm{pFSH}$ per $\mathrm{kg}$ $\mathrm{BW}$ produced a significantly higher number of total and transferable embryos with the highest recovery rate. At the same time, this dosage produced the lowest number of degenerated embryos and unfertilized oocytes, but no differences were observed among the treatment groups. Results indicated that $5 \mathrm{mg} \mathrm{pFSH}$ per $\mathrm{kg} \mathrm{BW}$ is suitable for producing embryos in the crossbred goats; however, further studies are needed to evaluate the interaction of FSH dosage with other factors (e.g., nutrition, age, surgery cycle) affecting superovulation performance in goats.

\section{REFERENCES}

Abdullah, R. B., N. Y. Shariffah, M. R. Rahman, and W. E. Wan Khadijah. 2012. Ovarian responses after superovulation with different dosages of oFSH in goats. Mal. J. Anim. Sci. 15:2125.

Abecia, J., C. Sosa, F. Forcada, and A. Meikle. 2006. The effect of under nutrition on the establishment of pregnancy in the ewe. Reprod. Nutr. Dev. 46:367-378.

Ali, M. S., M. A. M. Y. Khandoker, M. A. Afroz, and A. K. F. H. Bhuiyan. 2012. Ovarian response to different dose levels of follicle stimulating hormone (FSH) in different genotypes of Bangladeshi cattle. Asian Australas. J. Anim. Sci. 25:52-58.

Armstrong, D. T., A. P. Pfitzner, G. M. Warnes, and R. F. Seamark. 1983. Superovulation treatments and embryo transfer in Angora goats. J. Reprod. Fertil. 67:403-410.

Baldassarre, H., B. Wang, N. Kafidi, M. Gauthier, N. Neveu, J. Lapointe, L. Sneek, M. Leduc, F. Duguay, J. F. Zhou, A. Lazaris, and C. N. Karatzas. 2003. Production of transgenic goats by pronuclear microinjection of in vitro produced zygotes derived from oocytes recovered by laparoscopy. Theriogenology 59:831-839.

Baldassarre, H. and C. N. Karatzas. 2004. Advanced assisted reproduction technologies (ART) in goats. Anim. Reprod. Sci. 82-83:255-266.

Bindon, B. M., L. R. Piper, L. P. Cahill, M. A. Driancourt, and T. Oshea. 1986. Genetic and hormonal factors affecting superovulation. Theriogenology 25:53-70.

Cameron, A. W. N., K. M. Battye, and A. O. Trounson. 1988. Time of ovulation in goats (Capra hircus) induced to superovulate with PMSG. J. Reprod. Fertil. 83:747-752.

Chang, Z., X. Fan, M. Luo, Z. Wu, and J. Tan. 2006. Factors affecting superovulation and embryo transfer in Boer goats. Asian Australas. J. Anim. Sci. 19:341-346.

Conley, H. H. and H. W. Hawk. 1970. Intensification by intrauterine devices of sperm loss from the sheep uterus. Biol. Reprod. 2:401-407.

D'Occhio, M. J., D. Jillella, and B. R. Lindsey. 1999. Factors that influence follicle recruitment, growth and ovulation during ovarian superstimulation in heifers: opportunities to increase ovulation rate and embryo recovery by delaying the exposure of follicles to LH. Theriogenology 51:9-35.

Fonseca, J. F., J. H. Bruschi, I. C. C. Santos, J. H. M. Viana, and A. C. M. Magalhaes. 2005. Induction of oestrus in non-lactating dairy goats with different oestrous synchrony protocols. Anim. Reprod. Sci. 85:117-124.

Goel, A. K. and K. P. Agrawal. 2005. Ovulatory response and embryo yield in Jakhrana goats following treatments with PMSG and FSH. Trop. Anim. Health Prod. 37:549-558.

Gonzalez-Bulnes, A., J. Santiago-Moreno, M. J. Cocero, and A. 
Lopez-Sebastian. 2000. Effects of FSH commercial preparation and follicular status on follicular growth and superovulatory response in Spanish Merino ewes. Theriogenology 54:1055-1064.

Gonzalez-Bulnes, A., D. T. Baird, B. K. Campbell, M. J. Cocero, R. M. Garcia-Garcia, E. K. Inskeep, A. Lopez-Sebastian, A. S. Mcneilly, J. Santiago-Moreno, C. J. H. Souza, and A. VeigaLopez. 2004. Multiple factors affecting efficiency of multiple ovulation and embryo transfer in sheep and goats. Reprod. Fertil. Dev. 16:421-435.

Greve, T., H. Callesen, P. Hyttel, R. Hoier, and R. Assey. 1995. The effects of exogenous gonadotropins on oocyte and embryo quality in cattle. Theriogenology 43:41-50.

Holtz, W. 2005. Recent developments in assisted reproduction in goats. Small Rumin. Res. 60:95-110.

Kendall, N. R., A. Gonzalez-Bulnes, and B. K. Campbell. 2004. The use of urinary and recombinant human FSH preparations to induce superovulation in sheep and the effect on FSH and LH concentrations. Annual Meeting of British Society of Animal Science. 2004, Madrid, Spain. p. 59.

Kumar, J., J. C. Osborn, and A. W. N. Cameron. 1991. Luteinizing hormone and follicle stimulating hormone induce premature condensation of chromatin in goat (Capra hircus) oocytes. Reprod. Fertil. Dev. 3:585-591.

Lehloenya, K. C., J. P. C. Greyling, and S. Grobler. 2008. Effect of season on the superovulatory response in Boer goat does. Small Rumin. Res. 78:74-79.

Lehloenya, K. C. and J. P. C. Greyling. 2009. Effect of route of superovulatory gonadotrophin administration on the embryo recovery rate of Boer goat does. Small Rumin. Res. 87:39-44.

Lehloenya, K. C. and J. P. C. Greyling. 2010. The ovarian response and embryo recovery rate in Boer goat does following different superovulation protocols, during the breeding season. Small Rumin. Res. 88:38-43.

Lehloenya, K. C. 2013. Preliminary results evaluating a simplified superovulation protocol in Boer goats. Small Rumin. Res. 113:171-174.

Mani, A. U., W. A. C. Mckelvey, and E. D. Watson. 1992. The effects of low level of feeding on response to synchronization of oestrus, ovulation rate and embryo loss in goats. Theriogenology 38:1013-1022.
Menchaca, A., M. Vilarino, M. Crispo, A. Pinczak, and E. Rubianes. 2007. Day 0 Protocol: Superstimulatory treatment initiated in the absence of a large follicle improves ovarian response and embryo yield in goats. Theriogenology 68:11111117.

Moore, N. W. 1974. Multiple ovulation and ovum transfer in the goat. Proc. Aust. Anim. Prod. 10:246-249.

Murphy, B. D., R. J. Mapletoft, J. Manns, and W. D. Humphrey. 1984. Variability in gonadotrophin preparations as a factor in the superovulatory response. Theriogenology 21:117-125.

Noel, B., J. L. Bister, B. Pierquin, and R. Paquay. 1994. Effects of FGA and PMSG on follicular growth and LH secretion in Suffolk ewes. Theriogenology 41:719-727.

Nowshari, M. A., J. F. Beckers, and W. Holtz. 1995. Superovulation of goats with purified pFSH supplemented with defined amounts of pLH. Theriogenology 43:797-802.

Ryan, J. P., J. R. Hunton, and W. M. Maxwell. 1991. Increased production of sheep embryos following superovulation of Merino ewes with a combination of pregnant mare serum gonadotrophin and follicle stimulating hormone. Reprod. Fertil. Dev. 3:551-560.

Scaramuzzi, R. J., B. K. Campbell, J. A. Downing, N. R. Kendall, M. Khalid, M. Munoz-Gutierrez, and A. Somchit. 2006. A review of the effects of supplementary nutrition in the ewe on the concentrations of reproductive and metabolic hormones and the mechanisms that regulate folliculogenesis and ovulation rate. Reprod. Nutr. Dev. 46:339-354.

Veiga-Lopez, A., A. Gonzalez-Bulnes, J. A. F. Tresguerres, V. Dominguez, C. Ariznavarreta, and M. J. Cocero. 2006. Causes, characteristics and consequences of anovulatory follicles in superovulated sheep. Domest. Anim. Endocrinol. 30:76-87.

Xiao, Z. C., W. E. Wan Khadijah, R. B. Abdullah, and M. M. Rahman. 2013. Effects of hormonal administration and locality influence on superovulatory responses in goats. Indian J. Anim. Sci. 83:927-929.

Yuan, Y., L. An, B. Yu, T. Yang, and Y. Cheng. 2011. Effect of follicle stimulating hormone dosage, seasons and treatment frequency on superovulation in goats. Anim. Husb. Feed Sci. 3:20-22.

Zambrini, F. N. 2006. Ovulation Dynamics and Artificial Insemination in Fixed Time in Toggenburg Goats with Induced Oestrus. M.Sc. Thesis, Universidade Federal de Vic, osa, Vic, osa, MG, Brazil. 